\title{
Review of The Eternal Journey
}

To the Editor:

In the Fall 1999 issue of the Journal, Jenny Wade reviewed our book, The Eternal Journey. However, her review of the book was overshadowed by her perceptions of the authors. It was obvious that she does not think it possible for anyone affiliated with the Church of Jesus Christ of Latter-day Saints, more commonly known as Mormons, to detach themselves from their religious beliefs and write as objective social scientists. 
Wade claimed that the authors purposefully hid their religious affiliations in an attempt to brainwash the unaware. She wrote specifically:

The book seeks to "enlighten us about the reality, purposes, and meaning of life and death" (p. 11). However, the authors never state that their version of enlightenment, purpose, and meaning comes largely from a single source: the Church of Jesus Christ of Latter-day Saints (LDS, or Mormons). Mormon ideology permeates the entire book, but identification with this organization is not apparent to the average reader who is the audience for this mass-market book. As much as I respect these researchers' previous work, their affiliation makes a difference, given the reason for writing The Eternal Journey. Like controversial NDEr Betty Eadie, Lundahl and Widdison's concealment of their ideological bias is in marked contrast to the straightforward stance of other Mormon writers, such as Brent and Wendy Top (1993) and Arvin Gibson (1992). The nature of this bias is particularly relevant in a work purporting to reveal the "reality" about the "meaning of life." The LDS ideology is so pervasive in the book that it deserves treatment here before the contents of the book can be properly reviewed. (pp. 51-52, italics added)

Then she argued that the intent of the authors was to deceive the less sophisticated reader:

Thus the book, intended as an objective study of representative neardeath experiences from the general population conducted by objective scientists, is in fact a tract written by Mormons about mainly Mormon experiences. (p. 52, italics added)

She concluded her review by stating:

What I do question is their presentation as "scientific truth" in a work whose proselytizing ideology is never straightforwardly acknowledged. (p. 57, italics added)

We found it quite disturbing that Wade felt it necessary to attack the personal and professional integrity of the authors. She has accused us of being unprofessional, flagrantly unscientific, and purposively deceptive in our research. And the "evidence" she used was the fact that we are members of a particular religious group and that membership in this group makes us incapable of being objective. Her second criticism was based on the fact that a significant number of the sources utilized in the book were from "Mormon" sources. Thus, because the authors are Mormon and some of the sources in the book are from Mormon NDErs, the book was presumed to be unreliable, biased, and hence deceptive. Her argument was that we should have been straightforward in 
acknowledging our religious affiliation so that readers would be warned that they were about to be subjected to a heavy dose of Mormon theology. But Wade never specified what Mormon theology is, how it permeates the book, or how it distorts what was reported. At best she only hinted at areas in the book with which she personally disagrees as being the influence of Mormonism.

We would like to answer her charges. First of all, when we wrote this book, we were writing it as sociologists. We are both researchers and have taught courses on research methods and statistical analysis. Harold Widdison was also a program evaluator with the United States Atomic Energy Commission from 1960 to 1965 and Craig Lundahl was the Director of Research at Western New Mexico University. A feel for the research philosophy of both can be seen by reading Lundahl's earlier book, A Collection of Near-Death Research Readings. We are well aware that personal life experiences, culture, professional training, and values can be potentially biasing. While we do not believe that it is possible to eliminate all bias in research completely, it is possible to minimize its influence. Therefore, we decided that rather than start with a specific theory and its attendant hypothesis, we would do what is known in sociology as "grounded research" (Glaser and Strauss, 1965, 1967, 1968).

Grounded research entails attempting to locate all the sources of information that might relate to the phenomenon being studied, in this case the near-death experience. As data are collected, the researcher looks for common features between cases and for new types or categories. The researcher continues to collect data until new categories no longer occur. It is at this point that the researcher believes that he or she has discovered all the key variables and then tries to see how they relate to each other and as a whole. Thus the hypothesis and theory that emerge are derived from and grounded in the data.

We started with the rich and largely untapped body of data that is included in existing published sources. We identified every book, journal, magazine, diary, personal journal, or letter we could locate that included accounts of near-death experiences. Widdison personally reviewed 565 books and 1,289 articles, letters, and diaries dating from the mid-1700s to the present. We stipulated in our book that we had elected to limit our research strictly to first-person accounts of neardeath experiences, that is, to accounts of individuals who personally had an NDE or of others who witnessed a person having the experience in some way. We did not include any other accounts that were not recorded near-death experiences and we excluded any accounts from the reincarnation, mediumistic, psychic, and regression literature that 
were the very sources used by Wade to criticize our book. Wade complained about the book not utilizing materials from reincarnation and regression literature, but we made clear to the reader that we utilized only NDE accounts for the book. The result of this research is what was reported in the book. Wade never used any published NDEs-which again were the basis of the book-to support her criticisms.

In regard to Wade's frustration with the referencing style, we agree with her one hundred percent. When our manuscript was submitted to Warner Books, we had designed it for both the near-death researcher and the general public. The book was heavily documented and many points, issues, and themes had multiple citations. Our editor at Warner Books stated that the book would be marketed not as a textbook but as a book for the general public, and therefore the large number of references was distracting and had to be eliminated. We did manage to get our editor to accept the abbreviated but incomplete set of references that are in the book, but these include less than half of the original citations. As it currently stands, the reference section contains 90 of the original 178 references ( 20 Mormon, 70 other) and 292 of the original more than 400 citations (99 Mormon, the rest other).

Wade noted that "of the almost 300 citations, at least 150 were from identifiable Mormon sources" (p. 52). We suspect that what she referred to as "Mormon sources" were books printed in Utah. The fact is that all the publishers in Utah are not Mormon, and in those books or magazines that are published by individuals who are Mormon, not all the accounts recorded are Mormon. For example, at least 30 percent of the cases Arvin Gibson used in his three books were not Mormon NDErs. And the same is true for books by other authors. But this raises an important point. Is there some reason to suspect that Mormon NDErs have experiences that are quantifiably and qualitatively different from other people? It was our observation that their experiences were not significantly different in content. We did discover that the depth and breadth of the typical "Mormon" experience was different, but this fact was also noted by Kenneth Ring, Melvin Morse, Raymond Moody, George Ritchie, and Howard Storm, just to mention a few major researchers and experiencers.

We speculated as to why this might be the case and concluded that the following two factors could be responsible. First, Mormons are encouraged to keep records of the significant things that happen in their lives. The near-death experience definitely falls into this category and is therefore very likely to be recorded and preserved as part of a person's history. Second, the near-death experience is very complementary 
to Mormon theology and seen as an affirmation of belief, which is a further motivation for recording and sharing it.

As a result, there seem to be a lot more near-death experiences of Mormons available to analyze and research than their population would warrant. It would be interesting if other major religious traditions, cultures, and philosophies had a more substantial data base of NDEs that could be used to compare with those of Mormons. However, based on our experience in reviewing thousands of NDEs, it is our conclusion that there are no substantive differences. The accounts are very similar. It is how the experiencer interprets the significance of the experience in their lives that is likely to reflect a cultural influence. Therefore, it is imperative to have experiencers describe what happened in as much detail as possible with minimum input by the researchers. After the experience is described is the time to have experiencers talk about what it meant to them. Their interpretation of what they saw and experienced is where the cultural influence could show up.

On page 54, Wade noted as an example of our supposed selective perception (and perhaps of her own personal anticonservative Christian bias) the finding in the research primarily of Ring and of P. M. H. Atwater that NDErs move away from traditional, organized religions. On page 61 of our book, The Eternal Journey, this same point was clearly stated. Again on page 54, Wade chastised us for making unqualified statements of certainty. Yet she also noted that we used qualifiers such as "... these children might well...."

Wade obviously has some problems with Mormonism or at least her perceptions of what Mormonism is. On page 54, she quoted from our book a reference relating to the importance of families. Then she asserted that "this conclusion is yet another Mormonism." But she did not say how or why she reached that conclusion. Evidently, if she does not agree with what was reported, it must be something associated with Mormonism and hence (a) incorrect and/or (b) a reflection of the authors' biases. Wade was troubled by our summary of activities in the Realm of Light: after asking a series of questions she concluded that our findings "may reflect a strong Mormon cultural overlay that might well be absent from other records" (p. 55, italics added). Has Wade examined the records to see if this is true, or has she made these accusations without documentation or data?

Wade's educational and professional bias was demonstrated in her comments on the top of page 56. Quoting from our book that "there is no 'menial' work in the spirit world" (p. 189), she noted, "yet people sweep streets, and women can expect to cook, perform other kitchen 
duties, weave cloth, and even make clothing" (p. 56). Her understanding of "menial" shows her cultural bias. The point being made in this segment of our book was that just being in the City of Light is an honor and that anything requested of the inhabitants they consider to be a privilege. By the way, many of the references from this section of the book were not taken from Mormon sources or Mormon accounts.

In her book review, Wade seemed to be saying that it should be a standard for all writers and researchers to report things such as religious affiliations that in some way might influence their research or publications. But should this be limited only to Mormons? We think not! If Mormon writers must identify themselves, it makes sense that individuals who are anti-religious, atheistic, or agnostic should also reveal this fact to the reader. Too many academicians hide behind their diplomas, projecting an aura of total objectivity and expertise when they are pushing their own agendas on the unwary reader, listener, or student. This in effect is what we have been accused of. However, there is more than one type of religious zeal that drives researchers and writers. Scientism is a form of religion with its equivalent high priests and oracles, that is, professors and researchers. In some ways they are just as zealous, if not more zealous, in promulgating their version of what constitutes truth or facts as the most evangelical preacher. We read Wade's own book, Changes of Mind (1996), expecting her to inform the reader explicitly of her ideological, philosophical, and theoretical biases. All we found were her academic qualifications and areas in which she has consulted. Are we to assume that everything Wade does is immune from any influence from her personal experiences, cultural influences, and academic orientations?

We are both social scientists and we are both members of the Church of Jesus Christ of Latter-day Saints; and believe that we can be good members of both groups. In this regard, we challenge Wade to review the thousands of recorded near-death experiences before 1997 (the period of time covered in the book) and prove that the near-death experiences of Mormons are significantly different from those of nonMormon NDErs.

We also issue the same challenge to Ring, who has recently joined Wade's criticism of our work (Ring, 2000). We would like to see both Wade and Ring conduct replication studies of NDEs documented before 1997 and we will see if their data or the organizational scheme for them are significantly different from what we reported. As for Ring's statement that the Mormons have "latched onto the NDE" (Ring, 2000, 
p. 230), that is completely inaccurate. It can be argued strongly that modern near-death research has latched onto the Mormon interest in these experiences, and that near-death researchers today are in essence confirming what Mormons knew 140 years ago (Lundahl, 1993-94).

Apparently, Ring insists that religious or spiritual phenomena are mutually exclusive from religion and can be separated or disconnected from religion. That is just not being realistic, based on the direction that systematic near-death research has taken. Can Ring simply dismiss research findings when they happen to collide with specific beliefs, be they religion or otherwise, and may reflect the very essence of this phenomenon? Is not the major purpose of science a search for the truth no matter where it may lead?

We strongly suspect that what Ring has accused us selectively of doing-using NDEs to promulgate a particular religious belief systemis actually what Wade and Ring are doing. Apparently, they disagree with our findings because those findings do not agree with their worldview or values. Ring admitted as much in his article when he wrote: “To $m e$, the original promise of the field of near-death studies has ... been betrayed" (Ring, 2000, p. 229, italics and ellipsis added). That is the same thing as saying I had a preconceived notion of the direction this research was supposed to take and, because it did not do that, I feel (the field has been) betrayed. Ring also argued that the values governing research in the field of near-death studies have been corrupted. What specific values was Ring referring to, and what values should govern scientific research and near-death research specifically? Is there a difference between how near-death research should be conducted and how other scientific investigations should be conducted? What appears to be going on here is that Wade and Ring have a bias against religion, especially Mormonism, and are using professional journals to further their anti-religious agenda. They do not believe that religious individuals can conduct objective research, and without doing any scientific research to objectify their claims, they attack the professional integrity of two fellow scientists and attempt to discredit the results of a scientific study. The issue is not whether the authors should have declared their religious affiliation in their book; since when was it a requirement for serious scientists to give such information? The real issue here is the study's findings and their implications for near-death research. Let the chips fall where they may, regardless of religious or other belief systems. In due time, the truth will prevail in spite of the beliefs of any one group or individual. 


\section{References}

Glaser, B. G., and Strauss, A. L. (1965). Awareness of dying. Chicago, IL: Aldine.

Glaser, B. G., and Strauss, A. L. (1967). The discovery of grounded theory. Chicago. IL: Aldine.

Glaser, B. G., and Strauss. A. L. (1968). Time for dying. Chicago, IL: Aldine.

Lundahl, C. R. (Ed.). (1982). A collection of near-death research readings. Chicago, IL: Nelson-Hall.

Lundahl, C. R. (1993-94). A nonscience forerunner to modern near-death studies in America. Omega, 28, 63-78.

Lundahl, C. R., and Widdison, H. A. (1997). The eternal journey: How near-death experiences illuminate our earthly lives. New York, NY: Warner Books.

Ring, K. (2000). Religious wars in the NDE movement: Some personal reflections in Michael Sabom's Light \& Death. Journal of Near-Death Studies, 18, 215-244.

Wade, J. (1996). Changes of mind: A holonomic theory of the evolution of consciousness. Albany, NY: State University of New York Press.

Wade, J. (1999). [Review of The eternal journey: How near-death experiences illuminate our earthly lives]. Journal of Near-Death Studies, 18, 51-57.

Harold A. Widdison, Ph.D.

Professor of Sociology

Department of Sociology

Northern Arizona University

Flagstaff, AZ 86011

Craig R. Lundahl, Ph.D.

Professor Emeritus of Sociology and Business Administration

Chair Emeritus, Department of Social Sciences

Western New Mexico University

Silver City, NM 88062 